\title{
A-Ring Modified Betulinic Acid Derivatives as Potent Cancer Preventive Agents
}

\author{
Hsin-Yi Hunga,e , Kyoko Nakagawa-Goto a,b, Harukuni Tokudac ${ }^{\mathrm{c}}$, Akira lida ${ }^{\mathrm{d}}$, Nobutaka

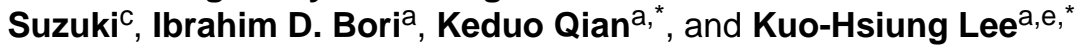 \\ aNatural Products Research Laboratories, Eshelman School of Pharmacy, University of North \\ Carolina, Chapel Hill, North Carolina 27599-7568, USA \\ bDivision of Pharmaceutical Sciences, Graduate School of Natural Science and Technology, \\ Kanazawa University, Kakuma-machi, Kanazawa 920-1192, Japan \\ 'Department of Complementary and Alternative Medicine, Clinical R\&D Graduate School of \\ Medicine Science, Kanazawa University, 13-1 Takara-machi, Kanazawa 920-8640, Japan \\ dFaculty of Agriculture, Kinki University, Nara 631-8505, Japan \\ eChinese Medicine Research and Development Center, China Medical University and Hospital, \\ Taichung 401, Taiwan
}

\begin{abstract}
Ten new 3,4-seco betulinic acid (BA) derivatives were designed and synthesized. Among them, compounds 7-15 exhibited enhanced chemopreventive ability in an in vitro short-term 12-Otetradecanoylphorbol-13-acetate (TPA) induced Epstein-Barr virus early antigen (EBV-EA) activation assay in Raji cells. Specifically, analogs with a free C-28 carboxylic acid, including $\mathbf{7}$, $\mathbf{8 , 1 1}$, and 13, inhibited EBV-EA activation significantly. The most potent compound $\mathbf{8}$ displayed $100 \%$ inhibition at $1 \times 10^{3} \mathrm{~mol}$ ratio/TPA and $73.4 \%, 35.9 \%$, and $8.4 \%$ inhibition at $5 \times 10^{2}, 1 \times$ $10^{2}$, and $1 \times 10 \mathrm{~mol}$ ratio/TPA, respectively, comparable with curcumin at high concentration and better than curcumin at low concentration. The potent chemopreventive activity of novel seco Aring BAs ( $\mathbf{8}$ and 11) was further confirmed in an in vivo mouse skin carcinogenesis assay.
\end{abstract}

\section{Keywords}

Betulinic acid; seco A-ring; Chemopreventive; EBV-EA

The concept of chemoprevention has grown over the past few decades. Cancer is a multistage process, and the question of how to stop the progression stage of its development has gradually drawn increasing attention. ${ }^{7}$ The Epstein-Barr virus early antigen (EBV-EA) activation assay was been established to quickly evaluate chemopreventive activity in vitro, ${ }^{8}$ while a two-stage mouse skin carcinogenesis assay can further assess in vivo activity. ${ }^{9}, 10$ Development of these biological assays has greatly facilitated research on chemopreventive agents.

\footnotetext{
(C) 2013 Elsevier Ltd. All rights reserved.

*Corresponding authors. Tel. : +1 9198835306 (K. Q. ); Tel. : +1 919962 0066; Fax: +1 9199663893 (K. -H. L. ). kdqian@unc.edu (K. Qian), khlee@unc.edu (K. -H. Lee).

Publisher's Disclaimer: This is a PDF file of an unedited manuscript that has been accepted for publication. As a service to our customers we are providing this early version of the manuscript. The manuscript will undergo copyediting, typesetting, and review of the resulting proof before it is published in its final citable form. Please note that during the production process errors may be discovered which could affect the content, and all legal disclaimers that apply to the journal pertain.
} 
Betulinic acid (BA, Figure 1) and its derivatives reportedly possess various pharmacological functions, such as anti-cancer, anti-HIV, anti-inflammatory, anti-malarial, and anti-bacterial effects. Prior modifications of BA have focused mainly on the C-3 hydroxyl, C-28 carboxylic acid, and C-30 allylic positions. ${ }^{1,2}$ Recently, we introduced short fatty acids at the $\mathrm{C}-3$ position of $\mathrm{BA}$ and the resulting BA analogs demonstrated excellent cancer chemopreventive activity in both EBV-EA activation and two-stage mouse skin carcinogenesis assays. ${ }^{3}$ Akihisha et al. also reported that compound $\mathbf{1}$ with a 3,4-seco lanostane structure exhibited inhibitory effects against EBV-EA activation in Raji cells. ${ }^{4}$ In addition, some limonoids [e. g. nomilin (2)] with an A-ring lactone showed anti-proliferative effects on neuroblastoma cancer cells (SH-SY5Y). ${ }^{5}$ The mechanism of action involved apoptosis induction, cancer cell cycle arrest and aneuploidic effects. ${ }^{5}$ Furthermore, other studies reported that 3,4-seco ursolic acid derivatives induced cell cycle arrest and apoptosis in a human bladder cancer cell line (NTUB1). ${ }^{6}$ Based on these discoveries, a group of novel 3,4-seco BA analogs 7-16 were designed to enhance the chemopreventive activity. Herein, this paper reports the design, synthesis and biological evaluation of these novel compounds.

3,4-Seco BA analogs 7-16 were designed and synthesized through oxepanone A-ring intermediates 5 and $\mathbf{6}$. A $N$-heptane acetamide side chain was included in our analog design $(9,10$ and 14-16), because this group enhanced the biological activity of BA in our prior studies. ${ }^{11}$ Initially, betulin, a commercially available pentacyclic triterpene, was oxidized with Jones reagent to provide compound $\mathbf{3}$ with a ketone at C-3 and carboxylic acid at C-28. Baeyer-Villiger reaction of $\mathbf{3}$ using 3-chloroperbenzoic acid (mCPBA) produced $\mathbf{5}$ with an oxepanone A-ring. Because prenyl-like groups have played an important role in cancer preventive effects in our prior studies, ${ }^{3}$ acid-catalytic lactone ring opening in $\mathrm{MeOH}$ was employed to produce the 4-methylene-3-methyl ester 7. Hydrolysis of 7 gave the corresponding dicarboxylic acid $\mathbf{8}$. Hydroboration-oxidation of $\mathbf{7}$ produced the alcohol 11, which was esterified using various acid anhydrides, such as 2,2-dimethylsuccinic and acetic anhydrides, to provide $\mathbf{1 2}$ and acetate $\mathbf{1 3}$, respectively. For the preparation of $N$-heptane acetamide analogs, the related carboxylic acids $\mathbf{3}$ and $\mathbf{1 3}$ were treated with oxalyl chloride and heptane-1,7-diamine followed by acetic anhydride to obtain 4 and 14, respectively. Analogs 6, 9 and 10 were prepared from 4 through the same procedure as for the preparation of $\mathbf{5 , 7}$ and $\mathbf{8}$. The methyl ester and acetate on $\mathbf{1 4}$ were hydrolyzed to produce $\mathbf{1 5}$, which was treated with dimethylsuccinic anhydride to provide $\mathbf{1 6 .}$

Compounds 6-16 were evaluated in an in vitro EBV-EA inhibition assay and the results are shown in Table 1. Bevirimat and BA were also evaluated and curcumin was used as a positive control. As seen in the results, 3,4-seco BA analogs showed substantial chemopreventive activity. Four compounds 7, 8, 11, and $\mathbf{1 3}$ significantly inhibited EBV-EA activation, showing $100 \%$ inhibition at the highest tested concentration. All four compounds contained a C-28 carboxylic acid and showed better activity than corresponding compounds with a C-28- $N$-heptane acetamide (compare 7/9, 8/10, 13/14). Three additional compounds with a $\mathrm{C}-28-\mathrm{N}$-heptane acetamide (compare $\mathbf{6}, \mathbf{1 5}, \mathbf{1 6}$ ) were also less active. The most active compound 8 also contained a C-3 carboxylic acid and C-4 methylene in addition to the C-28 carboxylic group. It displayed $100 \%$ inhibition at $1 \times 10^{3} \mathrm{~mol} \mathrm{ratio} / \mathrm{TPA}$, and 73. 4\%, 35 . $9 \%$ and $8.4 \%$ inhibition at $5 \times 10^{2}, 1 \times 10^{2}$, and $1 \times 10 \mathrm{~mol}$ ratio/TPA, respectively, with an $\mathrm{IC}_{50}$ value of $295 \mathrm{~mol}$ ratio/TPA. Even at the lowest concentration $(1 \times 10 \mathrm{~mol}$ ratio/TPA $), 8$ exhibited greater inhibitory activity than curcumin, a known cancer chemopreventive agent. This result may be because the $\mathrm{C}-5$ isopropenyl group is similar to a prenyl group, which has been an effective modification in cancer prevention research. ${ }^{3}$ Considering the C-3 substituent, compound $\mathbf{8}$ with a C-3 carboxylic acid was slightly more active than $\mathbf{7}$ with a C-3 methyl ester. Finally, regarding C-4 substituents, analog 7 with a C-4 methylene was slightly more potent than $\mathbf{1 1}$ and $\mathbf{1 3}$ with hydroxymethyl and acetoxymethyl, respectively. 
Two of the most active compounds, $\mathbf{8}$ and $\mathbf{1 1}$, were further evaluated in a mouse skin carcinogenesis assay (Figure 1). Mouse skin papillomas were induced by DMBA and promoted by TPA. Inhibitory effects of $\mathbf{8}$ and $\mathbf{1 1}$ were monitored and determined over 20 weeks by both the percentages of papilloma-bearing mice (Figure 2A) and the average numbers of papillomas/mouse (Figure 2B). Although skin papillomas still appeared, their occurrence was delayed for three weeks in both treated groups compared with the control group. At weeks 8 and 11, 50 and $100 \%$ of mice in the positive control group bore papillomas, while only $0-10 \%$ and $10-20 \%$ of mice in the 8- and 11-treated groups displayed papillomas. The average numbers of papillomas/mouse at week 8 and 11 were 1.2 and 2.7 for the positive control group, but only 0 and 0.4 , respectively, for the 8 -treated group. The in vivo results are quite promising and consistent with the in vitro data.

The structure-activity relationship (SAR) trends are summarized as follows. The 3,4-seco structural feature can significantly increase chemopreventive activity. A C-3 carboxylic acid is better than a methyl ester. A C-4 methylene is better than hydroxymethyl or acetoxymethyl groups. A C-28 carboxylic acid is considerably better than $N$-heptane acetamide. Among all new compound, 7, 8, 11, and $\mathbf{1 3}$ significantly inhibited TPA induced EBV-EA activation.

In this study, new BA derivatives were designed, synthesized and evaluated for cancer chemopreventive activity. Most of the newly synthesized compounds showed significant cancer prevention effects. In an in vitro EBA-EA assay, 8 was the most potent derivative with comparable inhibitory ability to curcumin, a known chemopreventive agent, at high concentration and better inhibitory ability at low concentration. Compounds $\mathbf{8}$ and $\mathbf{1 1}$ delayed occurrence of papillomas in an in vivo mouse skin carcinogenesis assay. These results provided convincing evidence that 3,4-seco modification can greatly enhance the chemopreventive activity of BA analogs.

\section{Supplementary Material}

Refer to Web version on PubMed Central for supplementary material.

\section{Acknowledgments}

This work was supported in part by NIH grant CA177584-01 from the National Cancer Institute and AI-33066-22 from the National Institute of Allergy and Infectious Diseases awarded to K. H. Lee.

\section{References and notes}

1. Qian K, Kuo RY, Chen CH, Huang L, Morris-Natschke SL, Lee KH. J Med Chem. 2010; 53:3133. [PubMed: 20329730]

2. Qian K, Yu D, Chen CH, Huang L, Morris-Natschke SL, Nitz TJ, Salzwedel K, Reddick M, Allaway GP, Lee KH. J Med Chem. 2009; 52:3248. [PubMed: 19388685]

3. a) Nakagawa-Goto K, Yamada K, Taniguchi M, Tokuda H, Lee KH. Bioorg Med Chem Lett. 2009; 19:3378. [PubMed: 19481937] b) Suzuki M, Nakagawa-Goto K, Nakamura S, Tokuda H, MorrisNatschke SL, Kozuka M, Nishino H, Lee KH. Pharm Biol. 2006; 44:178.c) Itoigawa M, Ito C, Tokuda H, Enjo F, Nishino H, Furukawa H. Cancer Lett. 2004; 214:1654.

4. Akihisa T, Nakamura Y, Tokuda H, Uchiyama E, Suzuki T, Kimura Y, Uchikura K, Nishino H. J Nat Prod. 2007; 70:948. [PubMed: 17488130]

5. Manners GD. J Agric Food Chem. 2007; 55:8285. [PubMed: 17892257]

6. Tu HY, Huang AM, Wei BL, Gan KH, Hour TC, Yang SC, Pu YS, Lin CN. Bioorg Med Chem. 2009; 17:7265. [PubMed: 19758808]

7. Gravitz L. Nature. 2011; 471:S5. [PubMed: 21430719] 
8. Ito Y, Yanase S, Fujita J, Harayama T, Takashima M, Imanaka H. Cancer Lett. 1981; 13:29. [PubMed: 6272961]

9. Konoshima T, Takasaki M, Tatsumoto T, Kozuka M, Kasai R, Tanaka O, Nie RL, Tokuda H, Nishino H, Iwashima A. Biol Pharm Bull. 1994; 17:668. [PubMed: 7920430]

10. Itoigawa M, Ito C, Ju-ichi M, Nobukuni T, Ichiishi E, Tokuda H, Nishino H, Furukawa H. Cancer Lett. 2002; 176:25. [PubMed: 11790450]

11. Huang L, Ho P, Lee KH, Chen CH. Bioorg Med Chem. 2006; 14:2279. [PubMed: 16314103]

12. Yu D, Wild CT, Martin DE, Morris-Natschke SL, Chen CH, Allaway GP, Lee KH. Expert Opin Investig Drugs. 2005; 14:681.

13. In vitro EBV-EA activation experiments: EBV-EA positive serum from a patient with nasopharyngeal carcinoma (NPC) was a gift from Professor H. Hattori, Department of Otorhinolaryngology, Kobe University. The EBV genome carrying lymphoblastoid cells (Raji cells derived from Burkitt's lymphoma) were cultured in $10 \%$ fetal bovine serum (FBS) in RPMI-1640 medium (Sigma R8758, USA). Spontaneous activation of EBV-EA in our subline of Raji cells was less than $0.1 \%$. The inhibition of EBV-EA activation was assayed using Raji cells (virus non-producer type) as described below. The cells were incubated at $37^{\circ} \mathrm{C}$ for $48 \mathrm{~h}$ in $1 \mathrm{~mL}$ of medium containing $n$-butyric acid ( $4 \mathrm{mM})$, TPA [32 $\mathrm{pM}=20 \mathrm{ng}$ in $2 \mu \mathrm{L}$ dimethyl sulfoxide (DMSO)] and various amounts of the test compounds dissolved in $2 \mu \mathrm{L}$ of DMSO. Smears were made from the cell suspension. The EBV-EA inducing cells were stained by the means of an indirect immunofluorescence technique. In each assay, at least 500 cells were counted, and the number of stained cells (positive cells) was recorded. Triplicate assays were performed for each compound. The average EBV-EA induction of the test compound was expressed as a ratio relative to the control experiment (100\%), which was carried out with n-butyric acid (4 mM) plus TPA (32 pM). EBV-EA induction was ordinarily around 35\%. The viability of treated Raji cells was assayed by the Trypan blue staining method. The cell viability of the TPA positive control was greater than $80 \%$. Therefore, only compounds that induced less than $80 \%$ (\% of control) of the EBV-active cells (those with a cell viability of more than $60 \%$ ) were considered able to inhibit the activation caused by promoter substances. Student's t-test was used for all statistical analysis. 


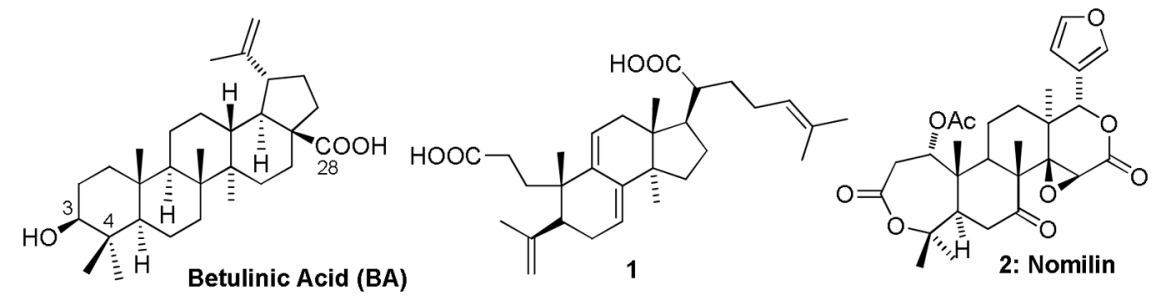

Figure 1. 

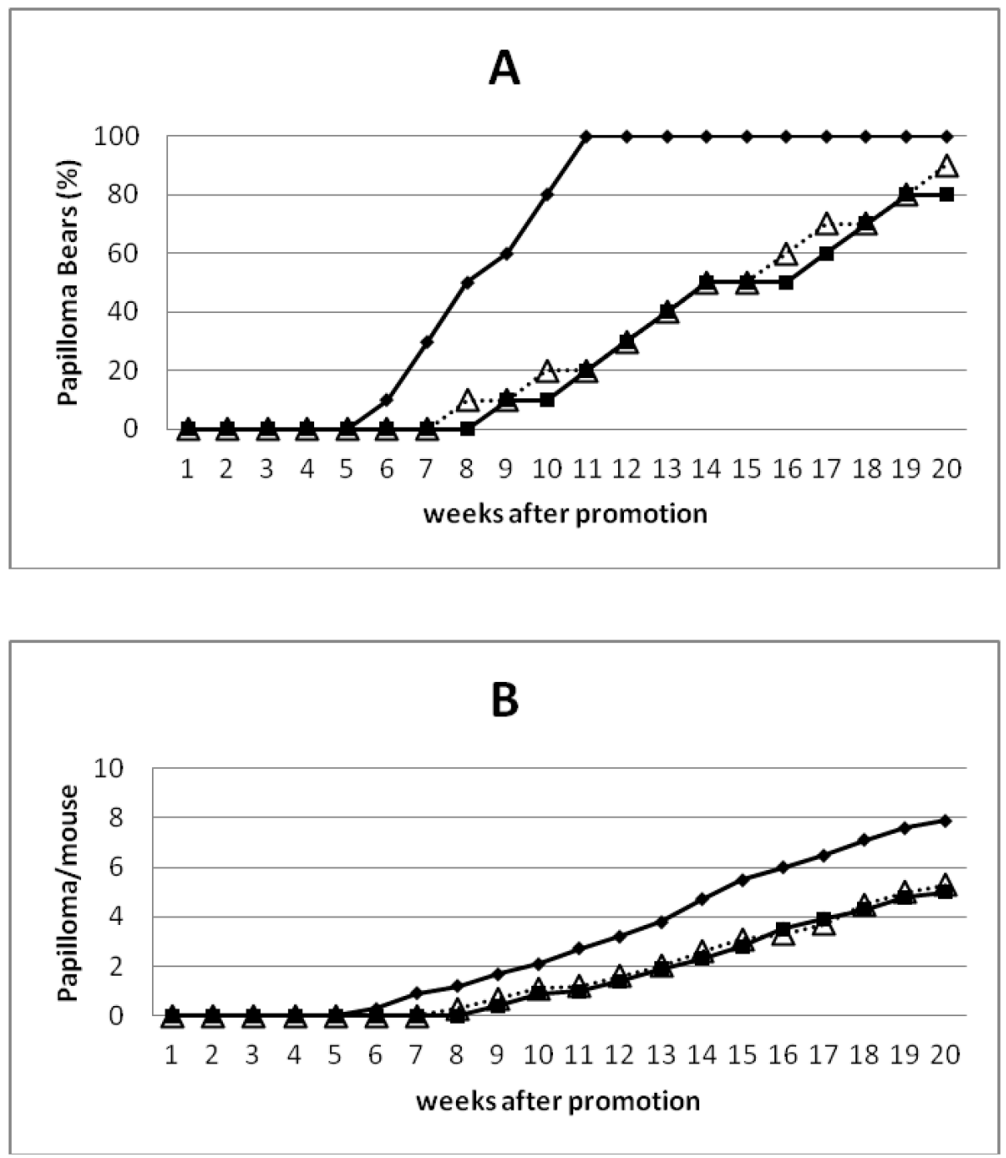

Figure 2. Inhibitory effects of compounds 8 and 11 on DMBA-TPA mouse skin carcinogenesis Tumor formation in all mice was initiated with DMBA $(390 \mathrm{nmol})$ and promoted with TPA (1. $7 \mathrm{nmol}$ ) twice weekly beginning 1 week after initiation. (A) Papilloma percentage in mice. (B) Average number of papillomas/mouse. $(\diamond)$ Control TPA alone; $(\triangle)$ TPA + compound 11 (85 nmol); ( $\mathbf{\square})$ TPA + compound 8 (85 nmol). After 20 weeks of promotion, a significant difference in the number of papillomas/mouse between the treated groups and the control group was evident $(\mathrm{p}<0.05)$. 


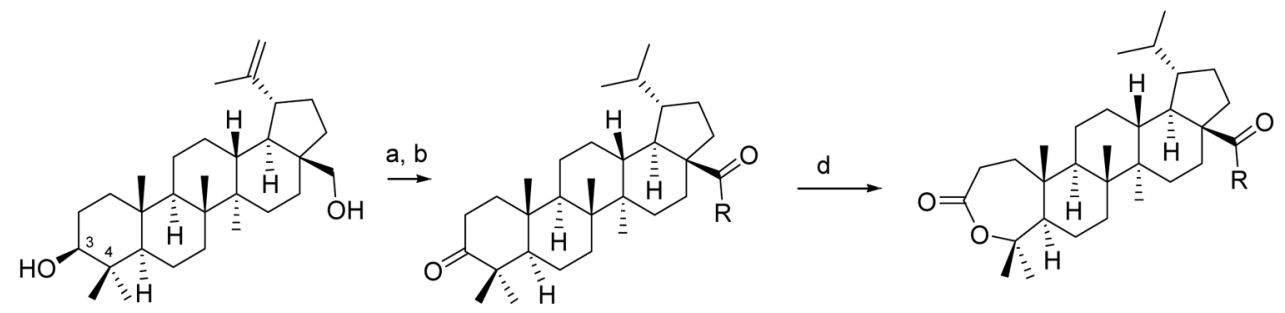

betulin c. $\begin{aligned} & 3 \mathrm{R}=\mathrm{OH} \\ & 4 \mathrm{R}\end{aligned}=\mathrm{NH}\left(\mathrm{CH}_{2}\right)_{7} \mathrm{NHCOCH}_{3}$ $5 \mathrm{R}=\mathrm{OH}$ $6 \mathrm{R}=\mathrm{NH}\left(\mathrm{CH}_{2}\right)_{7} \mathrm{NHCOCH}_{3}$

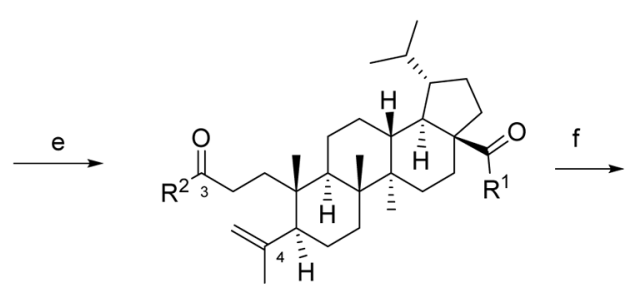

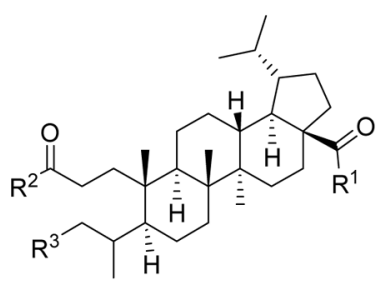

$$
\begin{aligned}
g\left(7 \mathrm{R}^{1}\right. & =\mathrm{OH}, \mathrm{R}^{2}=\mathrm{OMe} \\
8 \mathrm{R}^{1} & =\mathrm{OH}, \mathrm{R}^{2}=\mathrm{OH}
\end{aligned}
$$
g $69 \mathrm{R}^{1}=\mathrm{NH}\left(\mathrm{CH}_{2}\right)_{7} \mathrm{NHCOCH}_{3}, \mathrm{R}^{2}=\mathrm{OMe}$

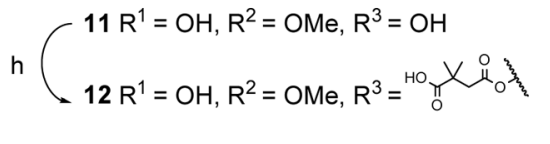

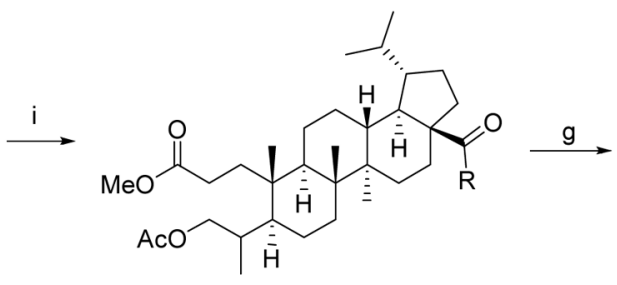

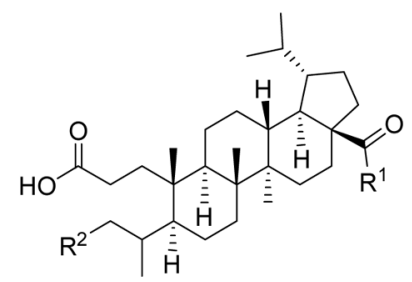

$\begin{aligned} 13 \mathrm{R} & =\mathrm{OH} \\ 14 \mathrm{R} & =\mathrm{NH}\left(\mathrm{CH}_{2}\right)_{7} \mathrm{NHCOCH}_{3}\end{aligned}$

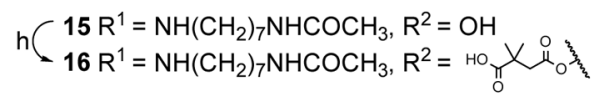

Scheme 1. Synthesis of 3,4-seco Betulinic Acid Derivatives

Reagents and Conditions: (a) Jone's oxidation, (b) Pd/C, HOAc, (c) 1) (CO) ${ }_{2} \mathrm{Cl}_{2}$, $\left.\mathrm{NH}_{2}\left(\mathrm{CH}_{2}\right)_{7} \mathrm{NH}_{2}, \mathrm{CH}_{2} \mathrm{Cl}_{2}, 2\right) \mathrm{Ac}_{2} \mathrm{O}$, 


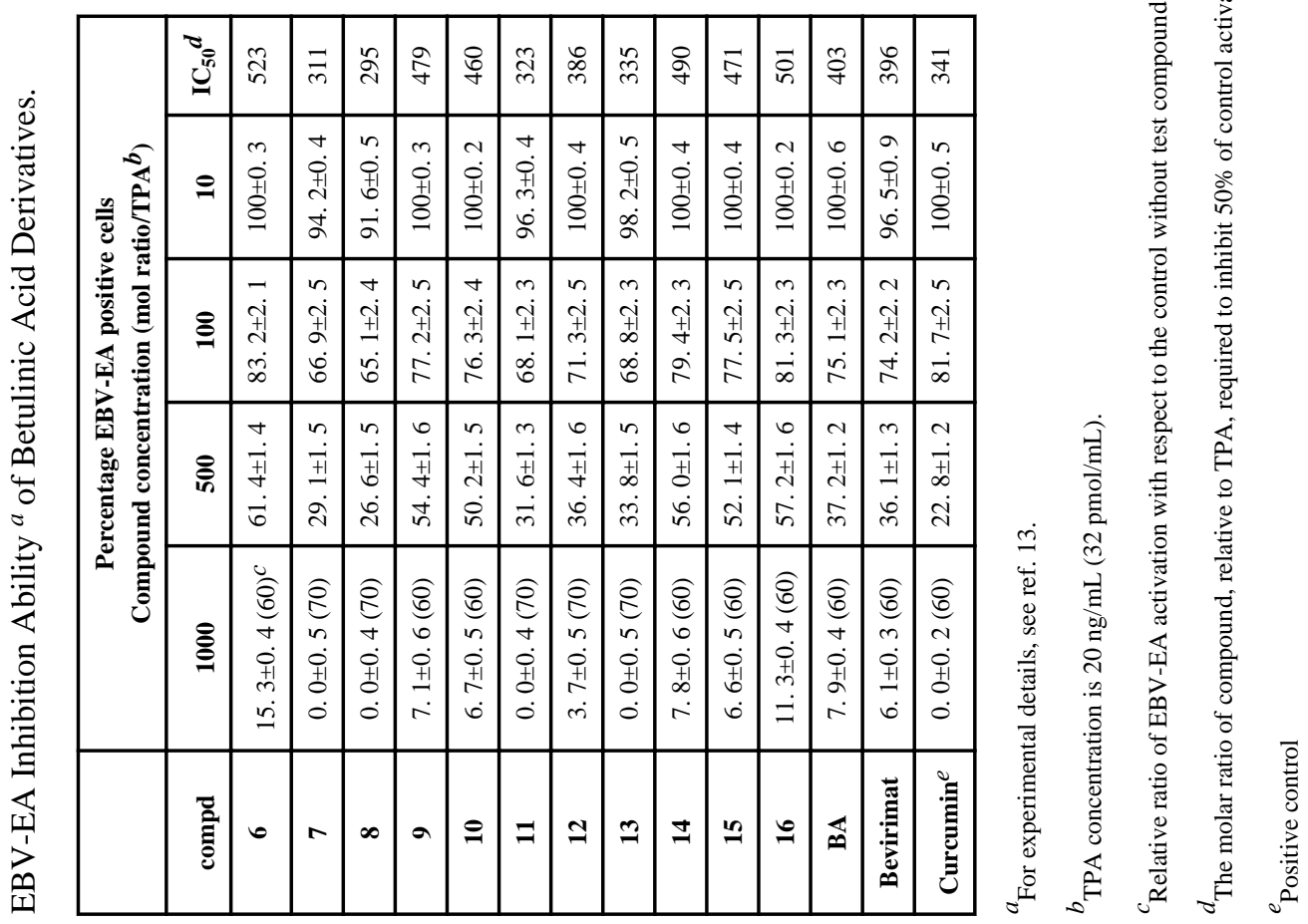

